\title{
US science education reforms 'still lack proper evaluation'
}

Washington. Ten years ago, a national report found that the United States was in danger of losing its competitive edge over other nations if action was not taken to improve its educational policy. A new report has found that although the government has made some headway in strengthening its role in science, mathematics, engineering and technology (SMET) education, much remains to be done.

The report, published last week under the title The Federal Investment in Science, Mathematics, Engineering, and Technology Education: Where Now? What Next? warns that the nearly 300 federally funded core programmes in these fields continue to be burdened by a lack of coordination, evaluation and accountability.

"Unfortunately, much of what was called for in that earlier report remains unfinished", says Karl S. Pister, chancellor of the University of California, Santa Cruz, and co-chair of the new report's 15 -member panel.

The panel was convened by the committee on education and human resources (recently renamed the committee on education and training) of the Federal Coordinating Council for Science, Engineering and Technology, or FCCSET.

Federal government spending in the area of evaluation was found to be woefully inadequate: funding for this activity constitutes less than one-half of one per cent (or US\$8 million) of the US\$2.2 billion spent as a whole by the 13 federal agencies that operate core SMET educational programmes.

Only one in five programmes has been fully evaluated; almost half have been neither evaluated nor monitored. Given the present climate of fiscal belt-tightening, the federal government can no longer afford the luxury of "investing in programmes that don't work", says Mary Budd Rowe, a professor of science education at Stanford University, and co-chair of the panel.

Although much of what is contained in the report is not new, one of its main recommendations is that federal agencies with programmes in SMET education should view and manage those programmes much like any "portfolio of investments". As such, the panel says agencies should place greater emphasis on coupling an assessment of educational needs to the unique capabilities of the various agencies.

Furthermore, the panel says that programmes must be evaluated more rigorously and the information "marketed" more aggressively so that teachers, students and researchers are kept abreast of new research findings and are better informed about the availability of new educational materials.

Diane Gershon

\section{Genetics test report urges moratorium on disclosure}

London. Individuals should not be expected to divulge information about their genetic history to insurance companies unless it relates to a known family history of genetic disease, or they are applying for an unusually large policy, according to a report published in London this week by the Nuffield Council for Bioethics.

The report is the first to be published by the council, which was formed in 1991 to consider ethical issues presented by advances in biomedical and biological research in the United Kingdom.

A working party set up by the council on genetic screening recommends that the government and the insurance industry should begin discussions soon about the future use of genetic data. In the meantime, it says, there should be a temporary moratorium on requiring disclosure of the results

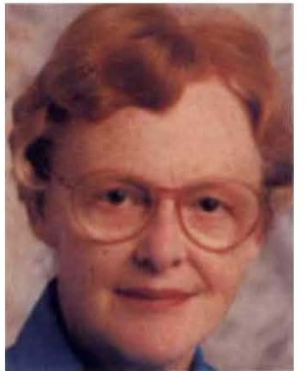

Lloyd: test results should remain secret. of genetic tests.

Brian Sharp of the Association of British Insurers says that at present no genetic testing is carried out for insurance purposes. "In a sense there aiready is a moratorium," he says. But even though insurance companies do not ask applicants if they have had a genetic test, they expect to be informed if a test has been carried out.

The report says that individuals should not be required to do so. "In the case of genetic screening, where there is still a lot of anxiety and fear, a genetic test result should not have to be divulged to insurers," says Dame June Lloyd, head of the working

party, who was formerly Nuffield professor of child health in the University of London.

Sharp says that although insurance companies have not debated the issues in depth, they are unlikely to oppose proposals concerning the confidentiality of results from random screening programmes. But insurers are also quick to point out that results of specific genetic tests can be to a potential policy holder's benefit.

Disclosure of test results to family members also raises the question of confidentiality. The difficulty here arises from the fact that unlike normal medical records, the results of genetic tests can have a direct, and possibly detrimental, effect on those related to the individual tested.

In this case the report says that individuals have a responsibility to tell family members of results of genetic screening. Health professionals should receive guidance on how they might be persuaded to do so.

In all other cases including disclosure to employers, however, an individual's rights should be paramount. Appropriate safeguards to maintain this confidentiality should be set up by anyone holding results of genetic screening, and the Department of Health should issue guidelines to this effect, says the report.

"The main message is that we hope that government will set up what we call a coordinating body to ensure that these things happen before screening programmes are set up," said Lloyd.

Other recommendations of the UK report, which is broadly in line with a similar report published recently by the US Institute of Medicine, include the provision of adequate counselling for anyone invited to enter a genetic screening programme before, both during and after testing.

Fiona Gammie

\section{Royal Society calls for electronic archive}

London. Scientific research could be damaged unless the UK adapts to the changes in funding of scientific publishing and academic libraries, warns a report published last week. A government-funded national electronic archive is one possible solution to the problem.

A report prepared by The Royal Society In conjunction with the British Library and the Association of Learned and Professional Society Publishers says that funding changes mean scientists must take tighter control of the amount of electronic information they send and receive.

The proposed electronic archive would be in the national interest, it says, because it would ensure results were accessible to future generations. It could be set up as part of the British Library, and would go some way to preserving all scientific publications as the range of topics become too wide for individual libraries to hold them all.

Other recommendations include routine training and funding provision for academics in the art of retrieving information.

But the report stresses the continued benefits of meeting face to face, rather than relying on electronic communication. And it says that academics should be encouraged to reduce their prose and keep research papers succinct - bringing a whole new meaning to the threat of cut-backs. 